\title{
Intracellular Association of Glycine Receptor with Gephyrin Increases Its Plasma Membrane Accumulation Rate
}

\author{
Cyril Hanus, Christian Vannier, and Antoine Triller \\ Laboratoire de Biologie Cellulaire de la Synapse Normale et Pathologique, Institut National de la Santé et de la Recherche Médicale, Ecole Normale \\ Supérieure, 75005 Paris, France
}

\begin{abstract}
Gephyrin, a tubulin-binding protein, is the core of inhibitory postsynaptic scaffolds stabilizing glycine receptors (GlyRs) and/or $\mathrm{GABA}_{\mathrm{A}}$ receptors. Previous ultrastructural studies in vivo and in vitro have reported a localization of gephyrin to intracellular cisternas during development or after glycinergic denervation (Seitanidou et al., 1992; Colin et al., 1996, 1998). These data were compatible with a traffic of this cytoplasmic, but membrane-associated, protein together with membrane proteins such as GlyR after exocytosis and/or endocytosis pathways. We have now investigated the consequences of a GlyR-gephyrin interaction on the localization and the dynamics of these two molecules in African green monkey kidney cells (COS-7) cells and in neurons transfected with green fluorescent protein-taggedgephyrin and myc-tagged GlyR $\alpha_{1}$ subunits. In these experiments, myc-tagged GlyR $\alpha_{1}$ contained, or did not contain, the gephyrinbinding sequence $(\beta \mathrm{gb})$ of the GlyR $\beta$ subunit. We report here that GlyR-gephyrin interaction localizes gephyrin to GlyR-containing organelles. Videomicroscopy and nocodazole treatment indicate that the movements of these vesicles are microtubule dependent. Expressing GlyR $\alpha_{1}$ with a thrombin cleavage site between the myc-tag and the $\mathrm{N}$ terminal of the GlyR $\alpha_{1}$ subunit (Rosenberg et al., 2001) allowed monitoring of newly inserted receptors in the cell surface. Using temperature changes to block GlyR in, and then release it from, the trans-Golgi network, we show that gephyrin accelerates the accumulation of GlyR at the cell surface. Therefore, our data strongly suggest that some GlyR clusters are associated with gephyrin on their way to the cell surface and that this association increases the accumulation of GlyR at the plasma membrane.
\end{abstract}

Key words: gephyrin; glycine receptor; surface insertion; clustering; videomicroscopy; neurons

\section{Introduction}

In the CNS, GABA and glycine are the two main inhibitory neurotransmitters, the latter predominating in the spinal cord (Moss and Smart, 2001). The corresponding receptors are concentrated to form microdomains containing glycine receptors (GlyR), $\mathrm{GABA}_{\mathrm{A}}$ receptors $\left(\mathrm{GABA}_{\mathrm{A}} \mathrm{R}\right)$ or a mixture of the two types of receptors $\left(\mathrm{GlyR}-\mathrm{GABA}_{\mathrm{A}} \mathrm{R}\right)$ in front of terminals releasing glycine, GABA, or the two neurotransmitters (Levi et al., 1999). As shown by antisense and knock-out experiments, gephyrin is required for the proper localization of GlyR and some $G_{A B A} R$ receptors at synapses (Kirsch et al., 1993; Essrich et al., 1998; Feng et al., 1998; Moss and Smart, 2001). Although glycine itself may play a role, the mechanism(s) that lead(s) to the specific accumulation of gephyrin in front of given presynaptic boutons is (are) still not understood (Kirsch and Betz, 1998; Levi et al., 1998). Most glutamate receptors (GluRs) in the plasma membrane are also accumulated at the postsynaptic density (PSD) with specific

Received Sept. 26, 2003; revised Nov. 29, 2003; accepted Dec. 1, 2003.

This work was supported by grants from Association Française contre les Myopathies (AFM) and from the Institut de Recherche sur la Moelle Epinière and by the Ministére de la Recherche et des Technologies of France (C.H.). We thank Drs. J. L. Bessereau and A. Bessis for helpful comments and criticism during manuscript preparation, Dr. M. Dahan for help in the analysis of GFP object trajectories, and the Vector Core of the University of Nantes supported by the AFM for providing the Ad.RSV.nlsLacZ.

Correspondence should be addressed to Dr. Antoine Triller, Laboratoire de Biologie Cellulaire de la Synapse Normale et Pathologique, Institut National de la Santé et de la Recherche Médicale U497, Ecole Normale Supérieure, 46 rue d'Ulm, 75005 Paris, France. E-mail: triller@wotan.ens.fr.

DOI:10.1523/JNEUROSCI.4380-03.2004

Copyright $\odot 2004$ Society for Neuroscience $\quad$ 0270-6474/04/241119-10\$15.00/0 distributions for AMPA receptors (AMPARs), NMDA receptors (NMDARs), or metabotropic GluRs (mGluRs) (Kennedy, 2000), and numerous PDZ [postsynaptic density-95 (PSD-95)/Discs large (Dlg)/zona occludens-1 (ZO-1)] domains containing molecules are part of the scaffolds stabilizing GluRs at the postsynaptic membrane (Craven and Bredt, 1998; Scannevin and Huganir, 2000).

Important questions are: Where do the interactions between molecules of the postsynaptic scaffold and receptors occur along its biosynthetic and secretion pathway? What are the consequences of these interactions, if any? and Could they contribute to the translocation of the membrane-associated scaffolding molecules to the plasma membrane? Interestingly, some studies have reported the presence of postsynaptic scaffold proteins in intracellular compartments containing receptors for neurotransmitters. This is the case of rapsyn for the acetylcholine receptor (AchR) (Marchand et al., 2000), PSD-95 for the NMDARs (ElHusseini et al., 2000), glutamate receptor-interacting protein/ AMPA-binding protein (GRIP/ABP) for the AMPARs (DeSouza et al., 2002), and Homer for mGluR (Roche et al., 1999). At the neuromuscular junction, rapsyn escorts the AChR along the secretory pathway (Marchand et al., 2000, 2002), suggesting that the delivery of receptor to the cell surface and/or to synapses could be regulated by its preassociation with components of the postsynaptic scaffold. This model could also apply to gephyrin, which has also been detected in association with intracellular somatic and dendritic vesicles during in vitro and in vivo devel- 
opment (Colin et al., 1996, 1998), or with vesicles in the vicinity of the Golgi apparatus after partial glycinergic denervation of mature Mauthner cells in the teleost fish (Seitanidou et al., 1992).

In the present study, we have investigated the effects of a GlyR-gephyrin interaction along the secretion pathway on GlyR accumulation in the plasma membrane. For this purpose, we have analyzed the behavior of GlyR and gephyrin in COS-7 cells and neurons cotransfected with green fluorescent protein (GFP)tagged gephyrin (Ge::GFP) and myc-tagged GlyR $\alpha_{1}$ subunits. To evaluate the effect of the GlyR-gephyrin interaction, the gephyrin-binding $(\beta \mathrm{gb})$ domain present in the GlyR $\beta$ subunit M3-M4 intracellular loop was inserted or not in the M3-M4 loop of GlyR $\alpha_{1}$ (GlyR $\alpha_{1} \beta \mathrm{gb}$ ) subunits. In transfection experiments the presence of the $\beta \mathrm{gb}$ sequence was shown previously (Meyer et al., 1995; Meier et al., 2000a,b; 2001) to promote GlyR-gephyrin interaction. We report here that this interaction localizes gephyrin to GlyR-containing vesicular compartments associated with microtubules. Videomicroscopy and nocodazole treatment indicate that the movements of Ge::GFP aggregates associated with GlyR are microtubule dependent. The use of a thrombin cleavage site downstream of the N-terminal myc-tag of GlyR $\alpha_{1}$ subunits (Rosenberg et al., 2001) allowed us to visualize receptors newly inserted in the cell surface. With this tool, we found that GlyRgephyrin interaction accelerates the accumulation of GlyR in the plasma membrane.

\section{Materials and Methods}

DNA constructs. The construction of GlyR $\alpha_{1}$ subunit cDNAs used in this study has been described previously (Meier et al., 2000a; Rosenberg et al., 2001). Namely, GlyR $\alpha_{1} \beta$ gb harbors the 18-residue gephyrin-binding sequence from the GlyR $\beta$ subunit (Meyer et al., 1995) within its M3-M4 loop. The GlyR myc-thr:: $\alpha_{1}$ and GlyR myc-thr:: $\alpha_{1} \beta$ gb subunits contain the thrombin cleavage amino acids sequence LVPRGS immediately after an N-terminal c-myc sequence. Gephyrin (clone p1; Prior et al., 1992) was fused to the green fluorescent protein (EGFP, obtained from the pEGFP-N1 plasmid, Clontech, Cambridge, UK) N terminal via GlyGlySer spacer sequence (Meier et al., 2000b). cDNA constructs were expressed in a eukaryotic expression vector derived from pEGFP-N1 (after removal of the EGFP coding sequence), allowing a cytomegalovirus promoter-driven expression. All endotoxin-free plasmids were prepared using the Qiagen (Hilden, Germany) protocols.

Cell culture and transient transfection. African green monkey kidney cells (COS-7) were grown in DMEM (Invitrogen, Cergy Pontoise, France) containing $10 \%$ fetal calf serum (Invitrogen) at $36^{\circ} \mathrm{C}$ in a $5 \%$ $\mathrm{CO}_{2}$ atmosphere. Transfection experiments were performed on subconfluent cultures (60\% confluency) plated on glass coverslips (Assistent, Winigor, Germany) using the FuGENE 6 (Roche Diagnostics, Meylan, France) method according to the manufacturer's protocol. Cells were usually transfected with $1 \mu \mathrm{g}$ of plasmid DNA in $35 \mathrm{~mm}$ dishes.

Primary cultures of spinal cord neurons were prepared from embryonic day 14 Sprague Dawley rats as described previously (Rosenberg et al., 2001). Routinely, cells were plated at a density of $7.510^{4}$ cells $/ \mathrm{cm}^{2}$ onto glass coverslips coated with $40 \mu \mathrm{g} / \mathrm{ml}$ poly-D,L-ornithine (Sigma, St. Louis) in $16 \mathrm{~mm}$ wells and grown in Neurobasal medium supplemented with $\mathrm{B} 27$ (Invitrogen) at $36^{\circ} \mathrm{C}$ in a $5 \% \mathrm{CO}_{2}$ atmosphere, for up to 3 weeks. Transfection of neurons was performed $2 \mathrm{~d}$ after plating by polyethylenimine-adenofection as described previously (Meier et al., 2000a) with $1 \mu \mathrm{g}$ of plasmid DNAs in $35 \mathrm{~mm}$ dishes.

A plasmid molar ratio of GlyR $\alpha_{1}$ subunits to gephyrin of 1 was used in all cotransfection experiments.

Videomicroscopy and depolymerization of microtubules. COS-7 cells were plated and transfected in customized $35 \mathrm{~mm}$ dishes with a glass bottom. For video recording, cells were incubated in air-MEM/chicken egg albumin (CEA) consisting of minimal essential medium without phenol red (Sigma) supplemented with $33 \mathrm{~mm}$ glucose, 2 mm glutamine,
$10 \mathrm{~mm}$ HEPES, $4 \mathrm{~mm} \mathrm{NaHCO}_{3}$, and $1 \mathrm{mg} / \mathrm{ml} \mathrm{CEA} \mathrm{(Sigma).} \mathrm{Cells} \mathrm{were}$ chosen after observation under differential interference contrast.

Nocodazole (Sigma) from a $10 \mathrm{~mm}$ stock (DMSO) was used at a final concentration of $1 \mu \mathrm{M}$ in air-MEM/CEA. The drug solvent DMSO delivered under the same conditions (same final volume and dilution factor) has no effect on microtubule integrity (data not shown).

Cell-surface myc tag trimming with thrombin. Cleavage of the c-myc tag from the cell-surface myc-th::GlyR subunits was performed $16-18 \mathrm{hr}$ after transfection after two washes of the cells with air-MEM supplemented with $2 \mathrm{mg} / \mathrm{ml}$ bovine serum albumin (BSA, Sigma). Cells were incubated with $0.5 \mathrm{U} / \mathrm{ml}$ thrombin (Roche) in the same medium either for $20 \mathrm{~min}$ at room temperature when intracellular myc-GlyR only was to be labeled (see Fig. 1), or for $1 \mathrm{hr}$ at $19.5^{\circ} \mathrm{C}$ when experiments required a temperature-induced trans Golgi network (TGN)-exit block (see Figs. 5, 6). Cells were then washed in the same medium without thrombin at room temperature or at $19.5^{\circ} \mathrm{C}$, and processed either for intracellular or surface myc-GlyR immunolabeling. Alternatively, they were returned to their initial culture medium at $37^{\circ} \mathrm{C}$ to let myc-GlyR reappear at the cell surface.

Immunofluorescence labeling. Immunofluorescence labeling was performed essentially as described previously (Rosenberg et al., 2001). Briefly, extracytoplasmic epitope tags were labeled before fixation by incubating living cells for $30 \mathrm{~min}$ at $4^{\circ} \mathrm{C}$ with primary antibodies diluted in air-MEM supplemented with $1 \mathrm{mg} / \mathrm{ml} \mathrm{BSA}$ and $0.1 \% \mathrm{w} / \mathrm{v}$ fish gelatin (FG; Sigma). After washing in the same medium, cells were fixed and processed as described below. Intracellular epitope tags were labeled selectively in cells treated with thrombin before fixation.

Cells were fixed in $4 \% \mathrm{w} / \mathrm{v}$ paraformaldehyde (PFA; Serva Feinbiochemica, Heidelberg, Germany) in PBS for 20 min either at $4^{\circ} \mathrm{C}$ (extracytoplasmic tag labeling) or at room temperature. For neurons, $4 \% \mathrm{w} / \mathrm{v}$ sucrose was added to the PFA solution. Cells were then quenched for 20 min at room temperature (RT) with $50 \mathrm{mM} \mathrm{NH}_{4} \mathrm{Cl}$ and when required were permeabilized with $0.1 \% \mathrm{w} / \mathrm{v}$ Triton $\mathrm{X}-100$ in PBS for 4 min at $4^{\circ} \mathrm{C}$. To block nonspecific immunoreactivity, cells were incubated for $30 \mathrm{~min}$ at RT with $0.2 \% \mathrm{w} / \mathrm{v}$ FG in PBS. Cells were incubated with antibodies diluted in $0.1 \%$ FG in PBS for $1 \mathrm{hr}$ (primary antibodies) or $45 \mathrm{~min}$ (secondary antibodies) at room temperature and washed extensively after each incubation. Cells were mounted in Vectashield (Vector Laboratories, Burlingame, CA) for observation.

Microtubule labeling was adapted from Ho et al. (1989). Cells were rinsed with PBS supplemented with $0.5 \mathrm{~mm} \mathrm{MgCl}_{2}$ and $0.8 \mathrm{mM} \mathrm{CaCl}_{2}$ and fixed for $15 \mathrm{~min}$ at $37^{\circ} \mathrm{C}$ with $3 \% \mathrm{w} / \mathrm{v}$ PFA and $0.02 \% \mathrm{v} / \mathrm{v}$ glutaraldehyde in PBS with $\mathrm{MgCl}_{2}$ and $\mathrm{CaCl}_{2}$. Cells were then successively dropped in methanol and acetone at $-20^{\circ} \mathrm{C}$ and were processed for immunolabeling.

The various antibodies were used at the following concentrations: mouse anti-myc (clone 9E10; Roche), $2 \mu \mathrm{g} / \mathrm{ml}$ (extracytoplasmic epitopes) or $1 \mu \mathrm{g} / \mathrm{ml}$ (total or intracellular epitopes); mouse anti- $\alpha$ tubulin (clone DM 1A, Ascites Fluid, Sigma), 1/1000; mouse antigephyrin (mAb7a; Alexis, QBiogen, Illkirch, France), $1.25 \mu \mathrm{g} / \mathrm{ml}$; rabbit anti-microtubule-associated protein (MAP2; Chemicon, Temecula, CA), 1/300; rabbit anti-GlyR $\alpha_{1} / \alpha_{2}$ (Zymed, San Francisco, CA), 1.25 $\mu \mathrm{g} / \mathrm{ml}$; goat anti-mouse-tetramethylrhodamine isothiocyanate, $7 \mu \mathrm{g} / \mathrm{ml}$; donkey anti-rabbit-indodicarbocyanine (Cy 5), goat anti-rabbit-FITC, and goat anti-mouse-Cy3, $1.5 \mu \mathrm{g} / \mathrm{ml}$. All secondary antibodies were from Jackson ImmunoResearch (West Grove, PA). For nuclear staining, 50 $\mathrm{ng} / \mathrm{ml} \mathrm{4}^{\prime}, 6^{\prime}$-diamidino-2-phenylindole (DAPI) was added to the secondary antibody solutions.

Western blotting and quantitative analysis. COS-7 cells were transfected in $20 \mathrm{~mm}$ wells and were cultured for expression for $0-25 \mathrm{hr}$. They were then incubated with $300 \mathrm{ng}$ of anti-myc antibody (clone 9E10, Roche) as described for the immunofluorescence labeling of extracytoplasmic epitopes. After extensive washing, cells were solubilized in $100 \mu \mathrm{l}$ of nonreducing Laemmli sample buffer. Fifteen and $30 \mu \mathrm{l}$ of each extract were loaded in a $7.5 \%$ acrylamide gel. For calibration, $0,0.125,0.25$, and $0.5 \mathrm{ng}$ of anti-myc antibody were loaded in the same gel. Electrotransfer was performed as described previously (Rasmussen et al., 2002). The blot was finally processed for enhanced chemiluminescence (ECL) detection (Amersham Biosciences, Europe GmbH, Saday, France) on Hyperfilm.

For calculation of the anti-myc amount present in the cell extracts, two films obtained after 2.5 and 5 min of ECL development were digitized 


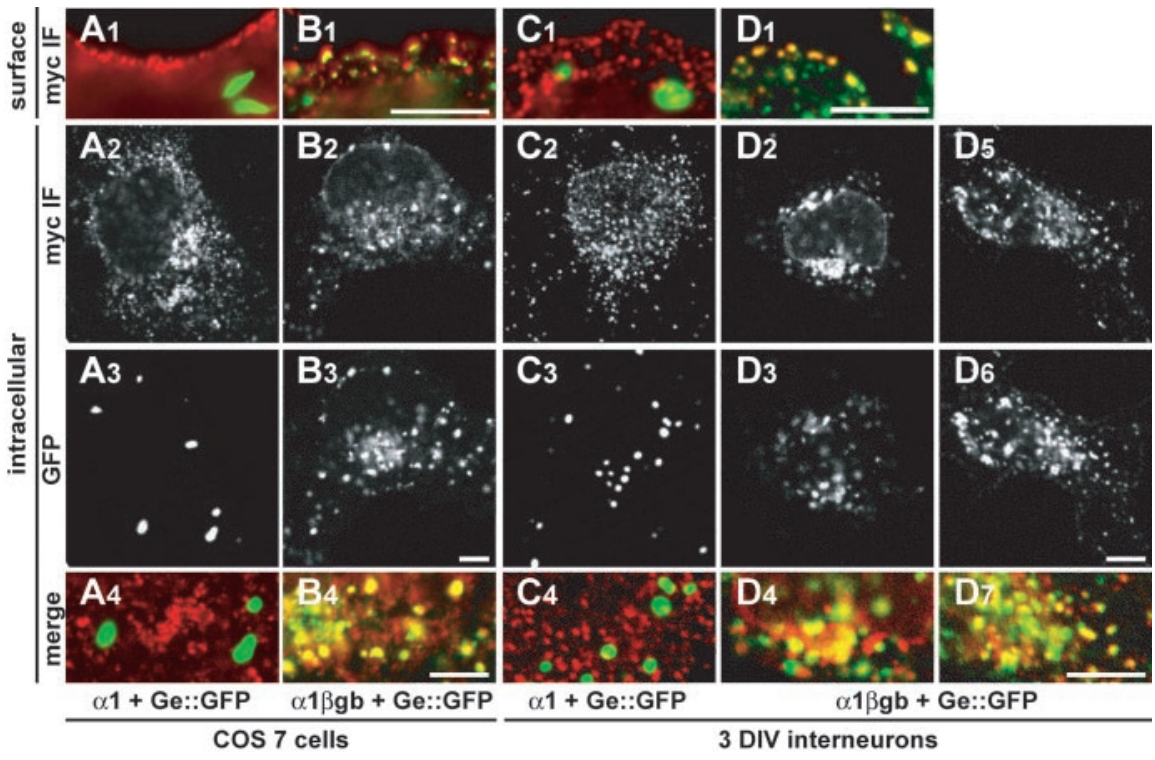

Figure 1. Gephyrin colocalization with intracellular GlyR. Immunofluorescence of myc-tagged GlyR $\alpha_{1}$ and $\alpha_{1} \beta g$ b subunits (red) in COS-7 cells $(A, B)$ and in 3 DIV spinal cord interneurons $(C, D)$ after cotransfection with gephyrin:::GFP (Ge::GFP, green). A1-D1, Cell-surface GlyR labeling. A2-D2, D5, Intracellular GlyR labeling (confocal sections). A3-D3, D6, Ge::GFP autofluorescence (confocal sections). A4 -D4, D7, Superimposition of lines 2 and 3 with GlyR (red) and Ge::GFP (green). A1-A4, C1-C4, Cells cotransfected with Ge::GFP and GlyR $\alpha_{1} ; B 1-B 4$, D1-D7, cells cotransfected with Ge::GFP and GlyR $\alpha_{1} \beta \mathrm{gb}$. Note that in the presence of the $\beta \mathrm{gb}$ sequence, GlyR and gephyrin are colocalized both at the cell surface and intracellularly. Scale bars, $5 \mu \mathrm{m}$.

with a numerical scanner (Epson Perfection 2450; Seiko Epson, Nagano, Japan) and the integrated signal associated with HRP activity was quantified for each lane with Metamorph software (Princeton Instruments, Trenton, NJ) after thresholding of the 16 bit pictures. For each film, values given by a known mass of anti-myc antibody were used to calculate the mean mass of anti-myc present in the cells extracts.

Fluorescence picture acquisition and quantitative analysis. Fluorescence pictures were usually acquired under $63 \times$ objective lenses with a Leica (Nussloch, Germany) DMR microscope equipped with a CCD camera (Coolsnap; Princeton Instruments) or with a spectral confocal Leica TCS/SP2 microscope. Time lapses of the gephyrin::GFP fluorescence were acquired on an inverted Leica DM-IRB microscope equipped for videomicroscopy with a CCD camera (Micromax; Princeton Instruments). Acquisition was done in black and white in 12 bit mode using appropriate filters or detection spectral windows. Analysis and quantification were done with Metamorph software (Princeton Instruments). When required, pictures were pseudocolored with Metamorph or Photoshop (Adobe Systems, San Jose, CA).

Fluorescent object tracking and calculation of diffusion coefficients. Gephyrin::GFP cluster trajectories were determined with a shape recognition algorithm from Metamorph. Values of the mean square displacement (MSD) were calculated with Matlab (MathWorks, Natick, MA) applying the relation MSD $(\mathrm{ndt})=(N-n)^{-1} \sum_{i=1}{ }^{N-n}\left(\left(x_{i+n}-x_{i}\right)^{2}+\right.$ $\left.\left(y_{i+n}-y_{i}\right)^{2}\right)$.dt (Saxton, 1997), where $N$ is the number of time-lapse frames, $n$ the number of time intervals taken simultaneously, and $x_{i}$ and $y_{i}$ the coordinates of an object on frame $i$. Slopes of the MSD plots between $n=2$ and $n=4\left(\operatorname{Slp}_{2-4}\right)$ were used to calculate apparent diffusion coefficients $\left(D_{\text {diff }}\right)$ according to the relation $\operatorname{Slp}_{2-4}=4 D_{\text {diff }}$ (Saxton, 1997).

Quantification of fluorescent puncta surface area and fluorescence intensity. Basically, a median filter was applied to the frames of video timelapse sequences and confocal sections of fixed cells after subtraction of the mean gray value corresponding to the fluorescence intensity measured outside cells ("out of cells" gray value). The surface area of fluorescent clusters and fluorescence intensity were calculated after thresholding of the pictures to allow the isolation of fluorescent clusters. All pictures used to compare cells transfected with GlyR $\alpha_{1}$ or GlyR $\alpha_{1} \beta \mathrm{gb}$ were acquired using the same parameter settings. Note that these settings were different between experiments. We checked that mean thresholding levels used for detection of clusters corresponding either to GlyR $\alpha_{1}$ or GlyR $\alpha_{1} \beta \mathrm{gb}$ were not significantly different (data not shown).

Subtractive time lapses used for analysis of gephyrin::GFP aggregate movements. Twoframe running subtraction of successive frames showing only moving structures were derived from video time-lapse sequences after removal of the mean out of cells gray value and application of a median filter with a homemade routine in Metamorph. Explored areas corresponding to the subtractive signal surface area were calculated frame by frame on the twoframe running subtraction sequences after automatic detection of the subtractive signal.

Quantification of GlyR-associated fluorescence per cell. Surface or intracellular GlyR-associated fluorescence in COS-7 cells (see Fig. 5) was quantified on pictures acquired under a $25 \times$ objective lens with a Leica DMR microscope. Pictured fields were chosen randomly on the basis of gephyrin::GFP fluorescence. The total field fluorescence intensity measured after subtraction of the mean out of cells gray value was divided by the number of transfected cells $(\approx 30$ in each field). For quantification of the fluorescence density associated with surface GlyR, we quantified the intensity of fluorescence in areas over nuclei projections delineated from DAPI staining. For each transfected cell, the fluorescence density was derived as the ratio of the fluorescence intensity over the projection of the nucleus by the surface area of the zone. The aim of this measurement is to avoid sampling bias linked to the variation of fluorescence between individual cells. Surface GlyR-associated fluorescence in neurons was quantified on confocal section $z$-series projections $(\approx 20$ sections taken at $200 \mathrm{~nm}$ depth intervals) acquired under a $63 \times$ objective lens. Pictured transfected neurons were chosen randomly on the basis of gephyrin::GFP fluorescence. For each transfected neuron (8-23 for each set of conditions), the total GlyR-associated fluorescence intensity was measured in the cell cytoplasm mapped according to MAP2 immunoreactivity and gephyrin::GFP-associated fluorescence, after subtraction of the mean out of cells gray value. Statistical significance was determined by means of Student's $t$ test using StatView Software (Abacus Concepts, Berkeley, CA).

\section{Results}

The insertion of the gephyrin-binding domain of the GlyR $\beta$ subunit ( $\beta \mathrm{gb}$ domain) in the $\alpha_{1}$ subunit is sufficient to mediate the binding of GlyR to gephyrin (Meyer et al., 1995; Meier et al., 2000a,b; 2001). We express here GlyR assembled with $\alpha_{1}$ or $\alpha_{1} \beta \mathrm{gb}$ subunits to analyze the consequences of GlyR-gephyrin intracellular interaction on the insertion of GlyR in the plasma membrane.

\section{GlyR $\alpha_{1} \beta$ gb localizes gephyrin::GFP to intracellular} vesicular structures

COS-7 cells or spinal cord neurons [3 d in vitro (DIV)] were cotransfected with gephyrin::GFP (Ge::GFP) and either GlyR $\alpha_{1}$ or GlyR $\alpha_{1} \beta$ gb subunits containing a thrombin cleavage site downstream to the myc epitope at the $\mathrm{N}$ terminal of the subunit (Rosenberg et al., 2001). For visualization of cell-surface GlyR, myc-tags were labeled in living cells before fixation. For visualization of intracellular GlyR, the surface myc-tags were trimmed off with thrombin, and the intracellular myc-tags were selectively labeled after fixation and permeabilization (Fig. 1). As described previously in transfected cells (Meier et al., 2000a,b; 2001), the GlyR-gephyrin interaction induces changes in the distribution 
pattern of the two molecules. In COS cells and in the absence of GlyR-gephyrin interaction, Ge::GFP formed large (1-3 $\mu \mathrm{m}$ diameter) intracellular aggregates not associated with GlyR (Fig. 1A3,A4); the latter were detected as small fluorescent puncta throughout the cytoplasm (Fig. $1 A 2, A 4)$. At the cell surface, GlyR was not associated with gephyrin (Fig. 1A1). GlyR-gephyrin interaction changed the gephyrin distribution dramatically: within the cytoplasm, Ge::GFP formed small aggregates colocalized with GlyR (Fig. $1 B 3, B 4)$, most likely corresponding to Ge::GFP associated with the TGN and vesicular elements of the post-Golgi secretion pathway. At the surface of neurons, and as we have already noted (Meier et al., 2000a; 2001; Rosenberg et al., 2001), GlyR $\alpha_{1}$ formed microclusters in the absence of interaction with gephyrin (Fig. 1C1). As in COS cells, Ge::GFP formed intracellular aggregates not associated with GlyR (Fig. $1 C 3, C 4)$. When the GlyR-gephyrin interaction was permitted by the presence of the $\beta$ gb sequence, GlyR and Ge::GFP were colocalized at the neuron surface (Fig. 1D1). Intracellularly, GlyR was detected around the nucleus and as small aggregates scattered in the cytoplasm (Fig. 1 D2,D4,D5,D7). Many of these GlyR puncta were colocalized with Ge::GFP (Fig. 1 D3,D4,D6,D7); $85.5 \pm 2 \%(n=7$ cells $)$ and $86.9 \pm 3 \%(n=7$ cells $)$ of Ge::GFP intracellular aggregates were colocalized with GlyR immunoreactivity in COS-7 cells and neurons, respectively.

Together, these results indicate that gephyrin may interact with GlyR within the cytoplasm, and likely along the secretion pathway. Furthermore, the high level of colocalization indicates that Ge::GFP fluorescence is reliable in following structures containing GlyR.

\section{GlyR-gephyrin interaction-dependent movements of Ge::GFP}

The movements of Ge::GFP were analyzed in living COS cells using videomicroscopy (Fig. 2). It was visible by eye that the small intracellular aggregates of Ge::GFP in the presence of interaction with GlyR (Fig. $2 A$ ) were more mobile than the large aggregates of Ge::GFP seen in the absence of interaction (Fig. $2 B$ ).

Time-lapse video sequences of Ge::GFP fluorescence were digitized at $0.2 \mathrm{~Hz}$ over variable periods (5-30 min). Ge::GFP objects formed in the presence of GlyR $\alpha_{1} \beta \mathrm{gb}$ were classified according to their localization (Fig. 2A): at the cell periphery, dispersed in the cytoplasm, or accumulated in the juxtanuclear area. We focused our analysis on the small aggregates moving in the cytoplasm. The small intracellular aggregates $\left(0.8 \pm 0.04 \mu \mathrm{m}^{2} ; n=170\right)$ emerged from the juxtanuclear area and moved rapidly with a global radial orientation, away from or toward the center of the cell. This behavior of Ge::GFP was observed only in the presence of the $\beta$ gb sequence. In the absence of the $\beta$ gb sequence, larger aggregates formed by Ge::GFP (Fig. 2B) $\left(3.14 \pm 0.63 \mu \mathrm{m}^{2} ; n=95\right)$ moved more slowly, with no obvious orientation.
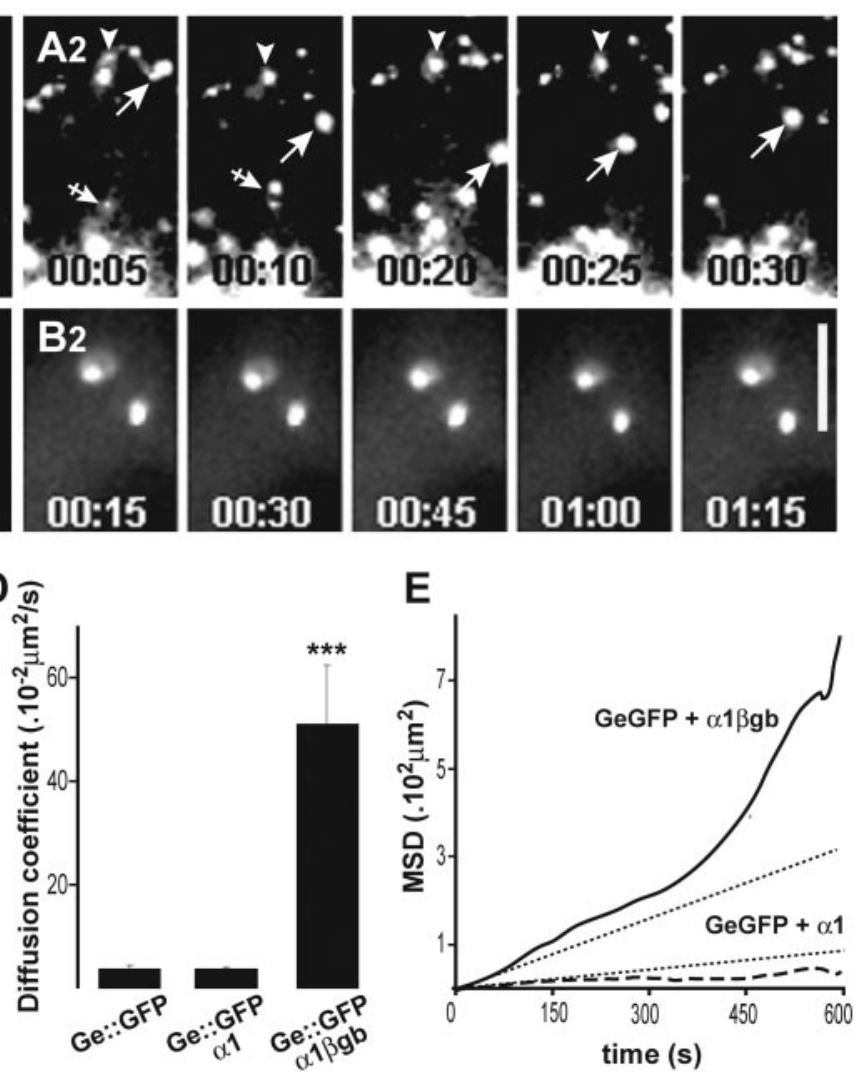
derived from time lapses of GFP fluorescence in cells cotransfected with Ge::GFP and GlyR $\alpha_{1} \beta \mathrm{gb}(A)$ or GlyR $\alpha_{1}(B)$ analyzed by when transfected alone (Ge::GFP), with GlyR $\alpha_{1}\left(\alpha_{1}+\right.$ Ge::GFP), or with GlyR $\alpha_{1} \beta \mathrm{gb}\left(\alpha_{1} \beta \mathrm{gb}+\mathrm{Ge}:: \mathrm{GFP}\right)$ (mean \pm SEM; for $n$ s a function of time, for Ge::GFP puncta in the presence (line) or absence (dashed line) of interaction with GlyR. The straight dotted lines represent the corresponding slopes at the origin. Scale bars: $A 1, B 1,10 \mu \mathrm{m} ; A 2, B 2,5 \mu \mathrm{m}$.

The centers of intracellular Ge::GFP aggregates were spotted and their trajectories were determined with an object tracking software (Fig. 2C). Movements were analyzed only over periods during which objects remained in the same focal plane. Diffusion coefficients of Ge::GFP aggregates alone or in cells cotransfected with GlyR $\alpha_{1}$ or GlyR $\alpha_{1} \beta$ gb subunits were compared (Fig. $2 D$ ). This analysis indicated that Ge::GFP aggregates formed with GlyR $\alpha_{1} \beta$ gb move $>10$ times more rapidly ( $p<10^{-4}$; Student's $t$ test) than large aggregates formed with Ge::GFP alone or with GlyR $\alpha_{1}$ (Ge::GFP, $3.7 \pm 0.410^{-2} \mu \mathrm{m}^{2} / \mathrm{sec}, n=45$; Ge::GFP + GlyR $\alpha 1,3.7 \pm 0.510^{-2} \mu \mathrm{m}^{2} / \mathrm{sec}, n=39$; Ge::GFP + GlyR $\left.\alpha_{1} \beta \mathrm{gb}, 50 \pm 1010^{-2} \mu \mathrm{m}^{2} / \mathrm{sec}, n=27\right)$. These values were derived from the slope of the curves depicting the variation of the MSD as a function of time (Fig. 2E) (Saxton, 1997). The positively curved function in the case of GlyR-gephyrin interaction is characteristic of a directed movement (Saxton, 1993) and compatible with a trajectory over microtubules. The negatively curved function in the absence of interaction with GlyR characterizes a confined movement compatible with the large Ge::GFP aggregates being trapped in the meshwork of the cytoskeleton and intracellular membranes.

These experiments and their analysis indicate that the binding of gephyrin to GlyR not only modifies the distribution of the former, but also affects the speed at which Ge::GFP moves in the 

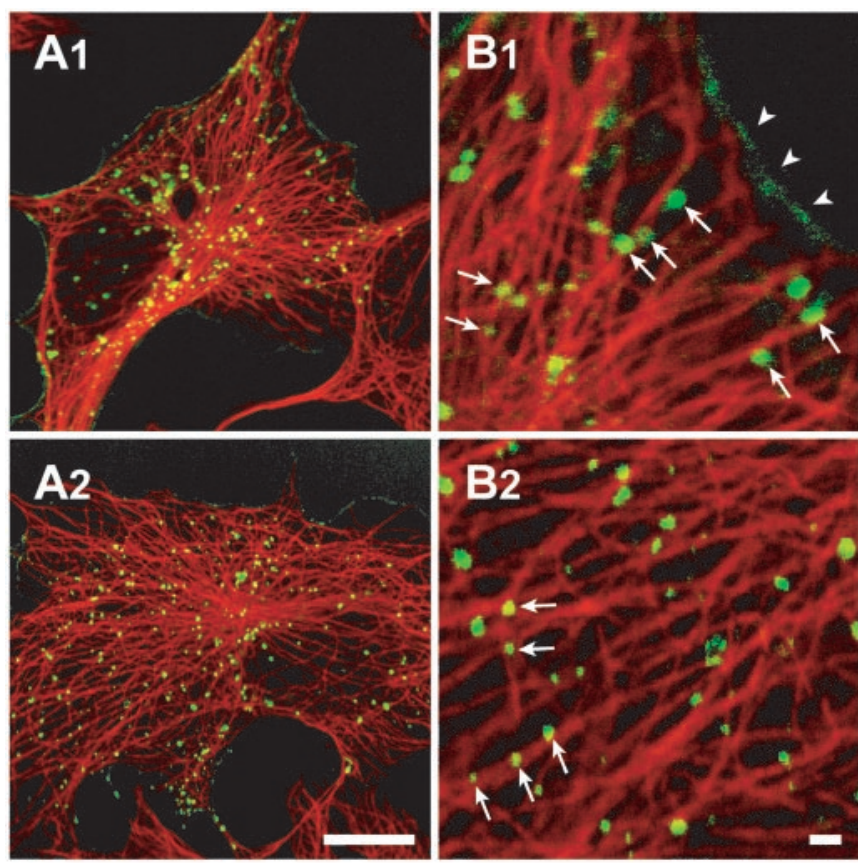

Figure 3. Association of GlyR-gephyrin::GFP with microtubules. $A, B$, Confocal sections of two COS-7 cells cotransfected with gephyrin::GFP and GlyR $\alpha_{1} \beta \mathrm{gb}$ at low-power $(A 1, B 1)$ and high-power $(A 2, B 2)$ magnifications. Microtubule immunoreactivity and Ge::GFP fluorescences are in red and green, respectively. Intracellular Ge::GFP puncta are associated with microtubules $(A 2, B 2$, arrows). Note that clusters at the cell periphery ( $A 2$, arrowheads) are not associated with microtubules. Scale bars: $A 1, B 1,10 \mu \mathrm{m} ; A 2, B 2,1 \mu \mathrm{m}$.

cell. Further, the radial and directed movement toward the plasma membrane is indicative of vesicles transiting in the cytoplasm along the secretion pathway (Toomre et al., 1999), the Ge::GFP aggregates being associated with GlyR (Fig. 1). Furthermore, the value of the diffusion coefficient measured for cytoplasmic Ge::GFP aggregates formed with GlyR $\alpha_{1} \beta \mathrm{gb}$ subunits, which is $50.10^{-2} \mu \mathrm{m}^{2} / \mathrm{sec}$, is comparable with that of vesicles tracking along microtubules (Toomre et al., 1999, Ahmari et al., 2000).

\section{GlyR-gephyrin movements are microtubule dependent}

In fixed cells, Ge::GFP clusters formed with GlyR $\alpha_{1} \beta \mathrm{gb}$ were not randomly distributed in the cytoplasm but were mainly associated with microtubules immunoreactivity (Fig. 3). Indeed, the large Ge::GFP aggregates formed with GlyR $\alpha_{1}$ overlapped with microtubules (data not shown), but they were not aligned along individual microtubules as transport vesicles would be: The diameter of these large blobs was much larger than the free space between individual microtubules delineated by their immunoreactivity.

The microtubule dependence of GlyR $\alpha_{1} \beta \mathrm{gb} / \mathrm{Ge}: \mathrm{GFP}$ movements was analyzed by videomicroscopy in cells exposed to nocodazole (Fig. 4). Various concentrations of the drug and exposure times were tested to determine the optimal conditions allowing a depolymerization of the microtubule network. A concentration of $1 \mu \mathrm{M}$ nocodazole was preferred. Under these conditions, most of the microtubular cytoskeleton was depolymerized after a $7.5 \mathrm{~min}$ exposure to the drug (Fig. 4A). After $10 \mathrm{~min}$, almost all microtubules were lost. Time lapses of the Ge::GFP clusters fluorescence were recorded for 3 min periods at a frequency of $0.33 \mathrm{~Hz}$, before treatment with nocodazole, and between 7 and $10 \mathrm{~min}$ after addition of the drug. The effect of
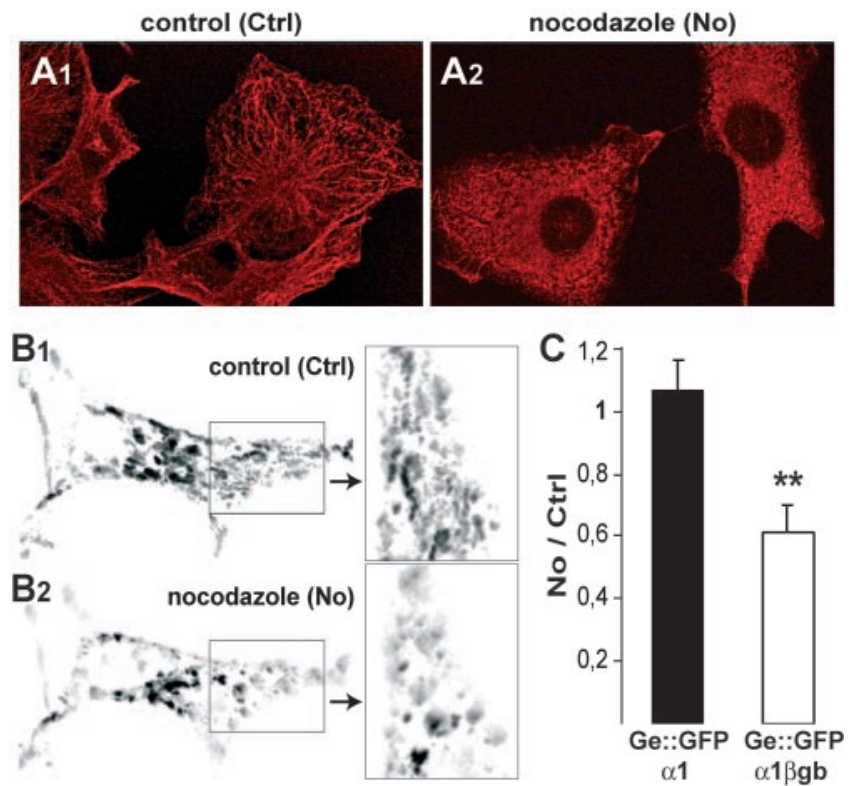

Figure 4. Influence of microtubule depolymerization on GlyR-gephyrin::GFP movements in COS cells. A, Tubulin immunoreactivity (projection of confocal section stacks) before (A1) and after (A2) nocodazole treatment demonstrating the depolymerization of the microtubules. $B$, "Subtractive projections" of Ge::GGP fluorescence time-lapse sequences (see text for details) of a cell transfected with GlyR $\alpha_{1} \beta$ gb recorded for 3 min before (B1) and during (B2) nocodazole treatment, at different magnifications. The signal (gray) corresponds to object displacements between two successive frames (the contrast has been inverted for a better visualization). $C$, Ratio of subtractive surface after ( $(\mathrm{No})$ to subtractive surface before (Ctrl) nocodazole treatment for individual cells (mean \pm SEM, the movements were analyzed in three and seven cells for GlyR $\alpha_{1}$ and GlyR $\alpha_{1} \beta \mathrm{gb}$, respectively). Although the movements of Ge::GFP puncta formed with GlyR $\alpha_{1}$ were not affected ( $\left(\right.$ ), the movements of Ge::GFP puncta formed with GlyR $\alpha_{1} \beta \mathrm{gb}$ decreased significantly ( $p<0.01$; Student's $t$ test) with nocodazole treatment.

nocodazole on aggregate dynamics was quantified with a subtractive method (Fig. 4B,C). Two-frame running subtractions of successive frames were derived from video time lapses and corresponded to transformed sequences in which only the moving structures remain. Comparison of the superimpositions of the subtractive time-lapse sequence frames indicated that the microtubule depolymerization dramatically reduced the displacements of Ge::GFP aggregates associated with GlyR $\alpha_{1} \beta g b$ subunits (Fig. $4 B)$. Note that gray traces corresponding to moving Ge::GFP aggregates were elongated before (Fig. 4B1) and rather round (Fig. 4B2) during the treatment. Within given cells, a certain level of heterogeneity remained. Even when the dynamics of Ge::GFP clusters was mostly reduced, some areas of the cell still remained unaffected, probably reflecting the persistence of a few intact microtubules. The total area corresponding to the fluorescent objects detected frame by frame on the two-frame running subtraction sequences was calculated for each cell (explored surface area). For normalization, the explored surface area measured during nocodazole treatment was divided by that measured before (Fig. $4 C$ ). As a consequence, values below 1 correspond to a decrease in explored surface area. This normalization allows the comparison for objects differing in size or shape (here, large and small aggregates formed with GlyR $\alpha_{1}$ and GlyR $\alpha_{1} \beta g \mathrm{~b}$, respectively). Nocodazole did not significantly affect the shape or the size of fluorescent aggregates (data not shown). Movements of the large Ge::GFP aggregates not interacting with GlyR were not modified by the depolymerization of microtubules (Fig. 4C). In contrast, nocodazole reduced by $40 \%$ the surface explored by Ge::GFP aggregates formed with GlyR $\alpha_{1} \beta$ gb. Nocodazole also 
induces a fragmentation of the Golgi apparatus elements (Ho et al., 1989). In our experiments, this fragmentation probably increased the dynamics of some Ge::GFP objects formed with GlyR $\alpha_{1} \beta \mathrm{gb}$ located in the juxtanuclear area, leading to an underestimation of the effect of nocodazole treatment.

These results support the notion that the movements of GlyR $\alpha_{1} \beta \mathrm{gb} / \mathrm{Ge}:: \mathrm{GFP}$ rely on an intact microtubule network. They emphasize the fact that gephyrin, a cytoplasmic protein, is traveling along microtubules together with its associated receptor, highjacking the secretion pathway.

\section{GlyR-gephyrin interaction modifies the accumulation of GlyR at the cell surface}

We then asked whether the GlyR-gephyrin association could modify the rate of GlyR accumulation in the plasma membrane. For this experiment, we took advantage of the thrombin cleavage site, which allows the selective visualization of newly inserted GlyR in the plasma membrane (Fig. 5A). This approach was first developed in our laboratory to localize the exocytosis sites of newly synthesized GlyR (Rosenberg et al., 2001). After $18 \mathrm{hr}$ of expression, transfected COS cells or neurons were incubated at $19.5^{\circ} \mathrm{C}$ for $1 \mathrm{hr}$ to synchronize the post-Golgi traffic. This temperature prevents the exit from the TGN, in which secretory proteins accumulate (Matlin and Simons, 1983; Griffiths et al., 1985). The thrombin treatment used to trim off myc sequences present at the cell surface was combined with the temperatureinduced block of TGN exit. The temperature was then shifted to $37^{\circ} \mathrm{C}$ to release the TGN traffic blockade and allow GlyRassociated myc immunoreactivity to reappear at the cell surface (restoration phase) under steady-state conditions. At various time points ranging from 0 to $90 \mathrm{~min}$ (Fig. 5A), cell-surface myc epitopes were labeled (Fig. 5B), and the GlyR-associated fluorescence was quantified (Figs. $5 C, D$ ).

The overall accumulation of GlyR $\alpha_{1}$ and GlyR $\alpha_{1} \beta \mathrm{gb}$ in COS cells cotransfected with Ge::GFP was first compared (Fig. 5B-D). For the quantification, large fields ( $25 \times$ objective lens) containing 20-30 transfected cells, were digitized, and the total fluorescence was measured. The fluorescence per cell was obtained by dividing total fluorescence by the transfected cell number. To validate this approach, we compared the amounts of cell-surface GlyR quantified at various times after transfection with immunofluorescence and with a Western blot (Fig. 5C). Cells taken at times $0,4,14$, and $25 \mathrm{hr}$ after transfection with myc-GlyR $\alpha_{1} \beta \mathrm{gb}$ subunits were incubated with anti-myc antibody to label cellsurface GlyR. A first set of cells was solubilized directly and the amount of anti-myc associated with the cell surface was quantified by Western blot analysis. A second set of cells, plated on glass coverslips, was fixed and processed for immunofluorescence labeling. After quantification of the samples, we compared the values given by the two assays at the corresponding time of expression. The significant correlation between the Western blot and fluorescence analysis (Fig. 5C, right) indicated that values obtained by fluorescence measurements reflected reliably the antimyc mass associated with the cell surface. We then compared in sister experiments the amount of intracellular and surface GlyR $\alpha_{1}$ and GlyR $\alpha_{1} \beta \mathrm{gb}$ at $t_{0}$ of the restoration phase (Fig. $5 D$ ). In cells cotransfected with Ge::GFP, the intracellular amounts of GlyR $\alpha_{1}$ or GlyR $\alpha_{1} \beta \mathrm{gb}$ were identical. In contrast, the surface-associated GlyR fluorescence was approximately two times higher in cells transfected with GlyR $\alpha_{1} \beta \mathrm{gb}$ subunits than in cells transfected with GlyR $\alpha_{1}$ subunits. We further ensured that the difference in surface GlyR amount did not result from specific rates of expression of the various plasmids. We compared the amount of surface
GlyR recovered after a restoration of $90 \mathrm{~min}$ in cells cotransfected with GlyR $\alpha_{1}$ or GlyR $\alpha_{1} \beta$ gb and either GFP or Ge::GFP (Fig. $5 D$ ). The amount of GlyR at the cell surface was increased only in cells cotransfected with GlyR containing the $\beta \mathrm{gb}$ domain and gephyrin. This demonstrated that this increase in GlyR expression is directly caused by the GlyR-gephyrin interaction. The amount of surface GlyR during the restoration phase (Fig. 5D,E) was then quantified at different time points. This quantification indicated that the GlyR-associated fluorescence increased faster in cells transfected with GlyR $\alpha_{1} \beta \mathrm{gb}$ subunits than in cells transfected with GlyR $\alpha_{1}$ subunits. It was already two times higher at $30 \mathrm{~min}$ for GlyR $\alpha_{1} \beta g b$ than for GlyR $\alpha_{1}$. Therefore, the interaction with gephyrin accelerates the accumulation of GlyR at the cell surface. The plots of the GlyR-associated fluorescence did not display a biphasic increase reflecting the TGN-exit block release (Griffiths et al., 1985). Actually, the acceleration of GlyR accumulation in these cells could reflect the combined effects of protein exocytosis/endocytosis processes.

The influence of intracellular GlyR-gephyrin interaction was also analyzed in neurons. For this purpose, neurons at 3 DIV were used under the same conditions as those described for COS cells. At this stage, few cells expressed a low level of endogenous GlyR and gephyrin (Bechade et al., 1996). The total fluorescence corresponding to surface GlyR was quantified using confocal section projections of transfected cells. The limits of neurons were mapped using MAP2 immunoreactivity and the Ge::GFP-associated fluorescence (Fig. 6A).

The number of fluorescence dots at the cell surface increased progressively with time after the release of the temperature block (Fig. 6A). They appeared on the soma and then on neurites. Fifteen minutes after the temperature shift, the amount of GlyR $\alpha_{1} \beta \mathrm{gb}$ was already 1.5 times that of GlyR $\alpha_{1}$, and this ratio remained stable until $90 \mathrm{~min}$. Comparison of fluorescence recovery on soma (Fig. 6 B2) and neurites (Fig. 6 B3) indicated that restoration occurred first at the soma. Interestingly, the GlyR restoration curves displayed a biphasic increase at the level of the soma only. This observation is consistent with previous experiments (Rosenberg et al., 2001) showing that exogenous GlyR $\alpha_{1}$ exocytosis occurs first in the somatic compartment and in proximal parts of dendrites. At the soma, comparison of the slopes of the restoration curves for GlyR $\alpha_{1}$ and GlyR $\alpha_{1} \beta g b$ showed that the highest increase was between 0 and $15 \mathrm{~min}$. This time value of 15 min is comparable with the half-time of protein delivery to the cell surface during the initial resumption of the TGN-exit that corresponds to the synchronized transport of molecules previously sequestered in the TGN (Griffiths et al., 1985; Rosenberg et al., 2001). GlyR $\alpha_{1}$ and GlyR $\alpha_{1} \beta g b$ surface clusters were analyzed on confocal sections after a restoration of $15 \mathrm{~min}$ (Fig. 6C,D). Number, surface area, and fluorescence intensities of GlyR $\alpha_{1} \beta \mathrm{gb}$ clusters were increased compared with that of GlyR $\alpha_{1}$ (Figs. $6 C, D)$. Surface GlyR $\alpha_{1} \beta g$ b clusters were colocalized with submembranous Ge::GFP (data not shown, but similar to those shown in Fig. 1D1).

These data indicate that gephyrin not only amplifies the rate of GlyR accumulation in the plasma membrane but also increases the number of receptors in clusters.

\section{Discussion}

Gephyrin is detected in the cytoplasm just before the onset of, and during, synaptogenesis in spinal cord neurons developing in vitro (Colin et al., 1996). Intracellular gephyrin was also found at birth in vivo, in rat ventral spinal cord neurons during inhibitory synaptogenesis (Colin et al., 1998). This intracellular gephyrin was 
A

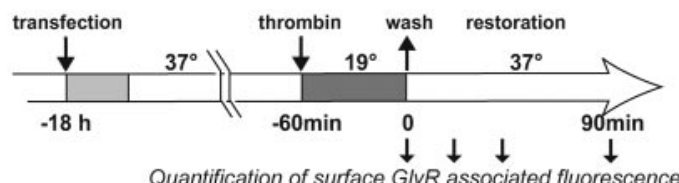

Quantification of surface GlyR associated fluorescence
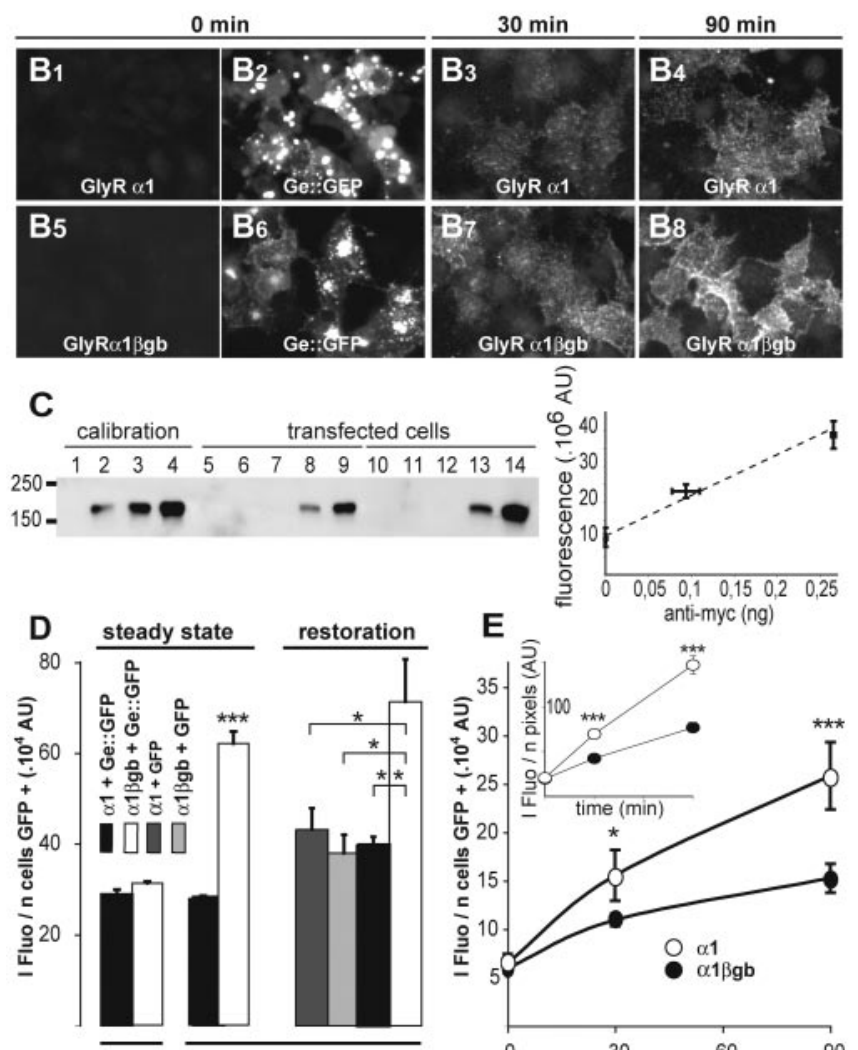

intracellular surface

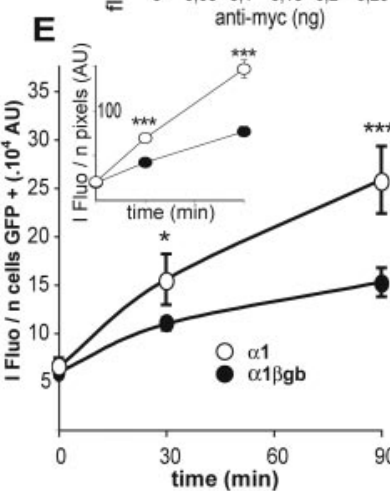

Figure 5. Gephyrin expression increases the amount of GlyR at the cell surface in COS cells. Cells cotransfected with GlyR $\alpha_{1}$ or GlyR $\alpha_{1} \beta$ gb subunits with a thrombin cleavable myc-tag, and gephyrin::GFP (Ge:::GFP). Accumulation of GlyR at the surface of COS-7 cells monitored after a temperature-induced block of the TGN exit (see Materials and Methods for details). A, Temporal sequence of the temperature-induced block of TGN exit, thrombin cleavage, and surface recovery of GlyR. Eighteen hours after transfection, cells were maintained for $1 \mathrm{hr}$ at $19.5^{\circ} \mathrm{C}$ $\left(t_{0}-60 \mathrm{~min}\right)$ in the presence or absence of thrombin to remove cell-surface myc-tags. Cells were then washed, returned to $37^{\circ} \mathrm{C}\left(t_{0}\right.$ of the restoration phase), and processed for immunolabeling of cell-surface myc-tags $\left(t_{0}+30\right.$ and $\left.t_{0}+90 \mathrm{~min}\right)$. Some cells directly fixed after the thrombin treatment $\left(t_{0}\right)$ were permeabilized before selective immunolabeling of intracellular GlyR. Fluorescence associated with GlyR was then quantified at the indicated time points. $B_{,}$ GlyR-associated immunofluorescence at the cell surface at various points of the restoration phase ( $B 1, B 5,0$ min; $B 3, B 7,30 \mathrm{~min} ; B 4, B 8,90 \mathrm{~min}$ ). $B 1-B 4$, Cells cotransfected with GlyR $\alpha_{1}$ and Ge::GFP; $B 5-B 8$, cells cotransfected with GlyR $\alpha, \beta g$ and Ge::GFP. Note the absence of myc immunoreactivity at the cell surface immediately after exposure to thrombin $(B 1, B 5)$ in cells displaying GFP fluorescence (B2, B6, same field as $B 1, B 5$, respectively). C, Surface GlyR expression in transfected cells quantified in parallel by Western blot and immunofluorescence analysis. Left, Immunoblot of anti-myc antibody: lanes $1-4: 0,0.125,0.25$, and $0.5 \mathrm{ng}$, respectively, of pure anti-myc antibody for calibration; lanes 5-14: $15 \mu \mathrm{l}$ (lanes 5-9) or $30 \mu \mathrm{l}$ (lanes 10-14) of cell lysates obtained 0 (lanes 6 and 11), 4 (lanes 7 and 12), 14 (lanes 8 and 13), and 25 hr (lanes 9 and 14) after transfection; lanes 5 and 10: lysates obtained $14 \mathrm{hr}$ after transfection and not exposed to anti-myc antibody. Molecular size markers are in kilodaltons. Right, Plot of surface myc-GlyR-associated fluorescence intensity as a function of surface anti-myc amount as quantified by Western blotting [mean mass \pm SEM expressed as nanograms in $15 \mu \mathrm{l}$; means were derived from $n=2$ pictures of the same blot and $n=12-18$ fields ( $25 \times$ objective lens) for mean fluorescence intensity] at the corresponding time of expression $(r=0.98 ; p<0.01$; regression analysis). D, Fluorescence associated with GlyR $\alpha_{1}$ or GlyR $\alpha_{1} \beta$ gb-bound anti-myc antibody immunoreactivity. Measurement over the whole field ( $25 \times$ objective lens) normalized by the number of transfected cells (mean \pm SEM). At steady states (18 hr after transfection), note the equivalent immunoreactivity of intracellular GlyR $\alpha_{1}$ and GlyR $\alpha_{1} \beta \mathrm{gb}$ in cells cotransfected with Ge::GFP and the increased GlyR $\alpha_{1} \beta \mathrm{gb}$ amount at the cell surface detected at the periphery of vesicles within the soma and dendrites. Furthermore, gephyrin-IR was also present around vesicles, at the periphery of the Golgi apparatus after the partial denervation of the goldfish Mauthner cell, an identified neuron of the teleost brainstem (Seitanidou et al., 1992). Similarly, in our cultures, gephyrin was found, in some neurons, to be associated with GlyR intracellular compartments, at the vicinity of the nucleus (Fig. 7). Together, these data suggest that gephyrin could transit toward the plasma membrane, in association with intracellular vesicles, possibly in association with the glycine receptor.

We have now investigated the intracellular effects of GlyRgephyrin interaction on the accumulation of GlyR in the plasma membrane. We analyzed in COS-7 cells and cultured spinal neurons the behavior of homomeric GlyR assembled with myctagged $\alpha_{1}$ subunits and GFP-tagged gephyrin (Ge::GFP). To evaluate the effects of the GlyR-gephyrin interaction, the gephyrinbinding sequence of the GlyR $\beta$ subunit ( $\beta \mathrm{gb}$ domain) was inserted or not in the GlyR $\alpha_{1}$ subunit M3-M4 loop (Meier et al., 2000a,b; 2001). With this strategy, we found that gephyrin was associated with intracellular GlyR and traveled in the cytoplasm along microtubules together with GlyR transport vesicles. Furthermore, the interaction with gephyrin increased the rate of GlyR accumulation in the plasma membrane.

\section{Gephyrin association with intracellular GlyR}

In cotransfection experiments, the gephyrin and GlyR colocalized intracellularly and formed small blobs. This was seen only when the $\beta$ gb sequence was inserted in the GlyR $\alpha_{1}$ M3-M4 loop. In contrast, when GlyR was not cotransfected, or when the $\beta \mathrm{gb}$ sequence was omitted, GFP-gephyrin formed the large aggregates described previously (Meyer et al., 1995). Here, the colocalization of gephyrin with GlyR in the juxtanuclear area and with small GlyR aggregates scattered in the cytoplasm, most likely corresponded to a relocalization of gephyrin on the GlyR secretion pathway. The microtubule-dependent movements of these small gephyrin aggregates formed in the presence of an interaction with GlyR further designated them as gephyrin associated with GlyR transport carriers because microtubules are known to facilitate the delivery of TGN-derived transport vesicles toward the appropriate membrane domain (Mays et al., 1994). The intracellular GlyR-gephyrin colocalization described here indicates that gephyrin may associate with GlyR along the secretion pathway.

Gephyrin was not associated with all GlyR-containing vesicles or with GlyR present around the nucleus in the perinuclear cistern (nuclear envelope), which is part of the endoplasmic reticulum. This observation strengthens the notion that the GlyRgephyrin interaction induced by the $\beta \mathrm{gb}$ sequence is not driven by the overexpression of the two molecules but is specific to the

\section{$\leftarrow$}

( $n=18-20$ fields from two experiments analyzed for each condition). During the restoration phase, note the increased expression of GlyR $\alpha, \beta \mathrm{gb}$ in the presence of Ge::GFP after $90 \mathrm{~min}$, but not in the presence of GFP, or in the absence of the $\beta \mathrm{gb}$ domain $(n=6-9$ fields analyzed for each condition after 90 min of restoration). E, Quantification of cell-surface GlyR-associated fluorescence during the restoration phase ( $n=14-20$ fields analyzed for each condition). Inset, Quantification analyzing the surface fluorescence density in transfected cells (see Materials and Methods) during the restoration phase (mean \pm SEM; $n=13-19$ fields containing 20-30 transfected cells from two experiments analyzed for each time point and each transfection condition). In both cases, the GlyR $\alpha_{1} \beta \mathrm{gb}$-associated fluorescence increased more rapidly than that of GlyR $\alpha_{1}$. Note that values of fluorescence associated with cell-surface and intracelIular GlyR at $t_{0}(D)$ and cell-surface GlyR during the restoration phase $(D, E)$ cannot be directly compared because different exposure times were used for the acquisition of fluorescence pictures. ${ }^{*} p<0.05 ;{ }^{* *} p<0.01 ;{ }^{* * *} p<10^{-4}$; Student's $t$ test. 
TGN to plasma membrane segment, and depends on additional mechanisms specifying the interaction at this level.

Effects of GlyR-gephyrin interaction on GlyR accumulation at the cell surface Comparison of surface GlyR recovery after a temperature-induced TGN-exit block in COS cells or in neurons showed that GlyR-gephyrin interaction increased the rate of GlyR accumulation in the plasma membrane. In COS cells, the amount of GlyR at the cell surface, $30 \mathrm{~min}$ after the resumption of the TGN-exit, was one and a half times higher in cells transfected with GlyR $\alpha_{1} \beta g b$ than in those transfected with GlyR $\alpha_{1}$ subunits, whereas their intracellular amount was identical just after the release of the TGN-exit block. In neurons, the use of cleavable tags and temperature block showed that the insertion of exogenous GlyR, in the plasma membrane, occurs first in the soma (Rosenberg et al., 2001). We now show that, in the presence of gephyrin, the highest difference in the rate of accumulation of GlyR $\alpha_{1}$ and GlyR $\alpha_{1} \beta \mathrm{gb}$ is between 0 and 15 min of recovery, a time interval compatible with the synchronized transport of molecules previously sequestered in the TGN during the initial resumption of the TGN-exit (Griffiths et al.,1985; Rosenberg et al., 2001). This observation indicates that gephyrin may accelerate GlyR externalization, as a result of an increased amount of GlyR being transported toward the neuronal surface. The effect of nocodazole treatment indicates that this transport is likely to be microtubule dependent, as is the transport between the TGN and the cell surface (Mays et al., 1994). The homology of a gephyrin domain with MAP2 (Prior et al., 1992), and its ability to bind tubulin (Kirsch et al., 1991) and the dynein light chain 2 (Dlc2; Fuhrmann et al., 2002) strengthen the notion that gephyrin could be involved in a microtubule-based transport. Indeed, Dlc2 is a common subunit for cytoplasmic dynein and myosin V (Naisbitt et al., 2000), which interacts with several kinesins (Langford, 2002). In addition, gephyrin also binds molecules controlling the actin cytoskeleton, such as profilin, which promotes actin $\mathrm{F}$ polymerization (Mammoto et al., 1998), and the rho guanosine exchange factor collybistin (Kins et al., 2000). Furthermore, our data indicate that GlyR is stabilized by gephyrin on, or very soon after, its insertion in the plasma membrane. This is consistent with the observation that removal of GlyR from the plasma membrane is prevented by gephyrin in transfected cells (T. Rasmussen and C. V., unpublished results). Actually, 15 min after the release of the TGN-exit block, interaction of $10^{-4}$; Student's $t$ test.
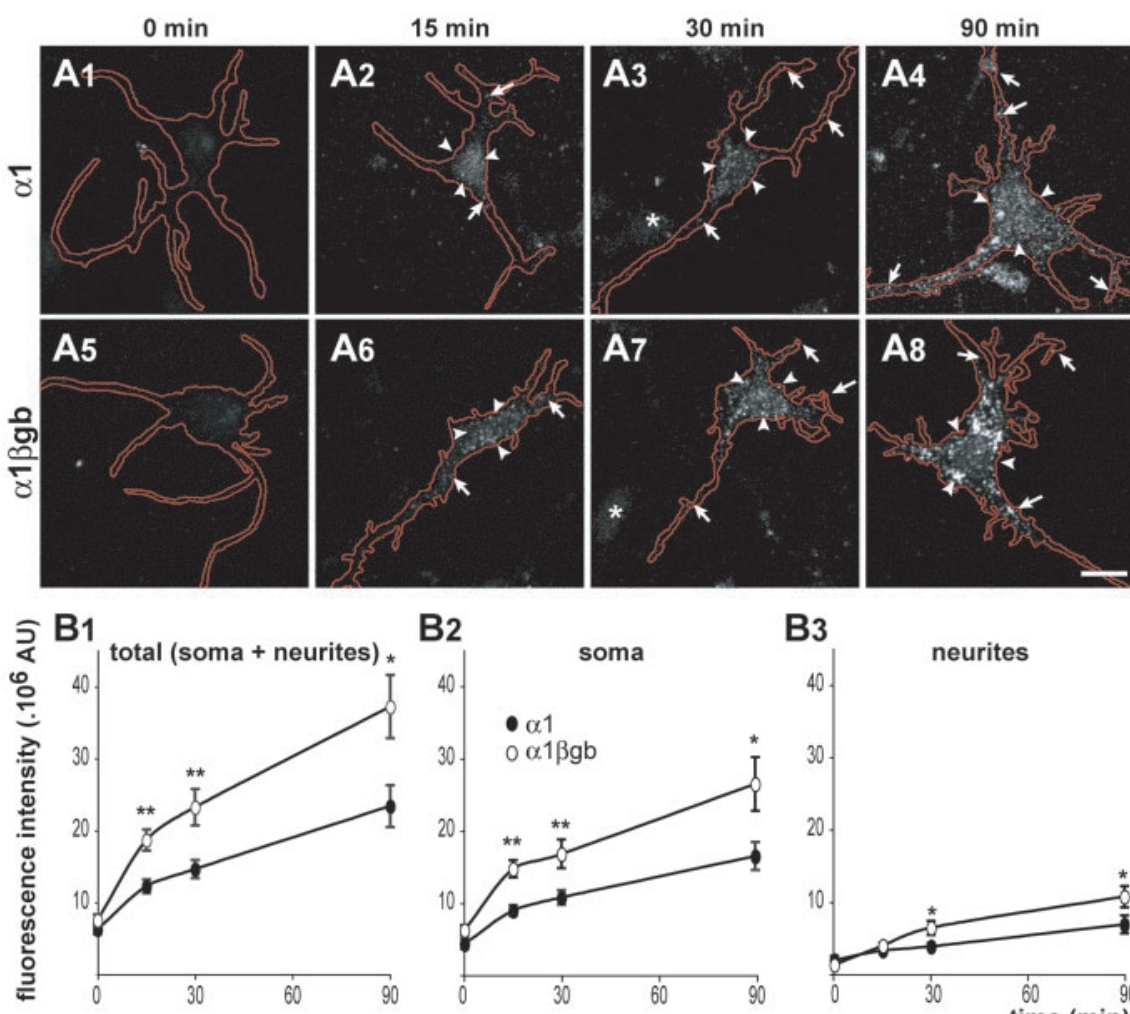

B2
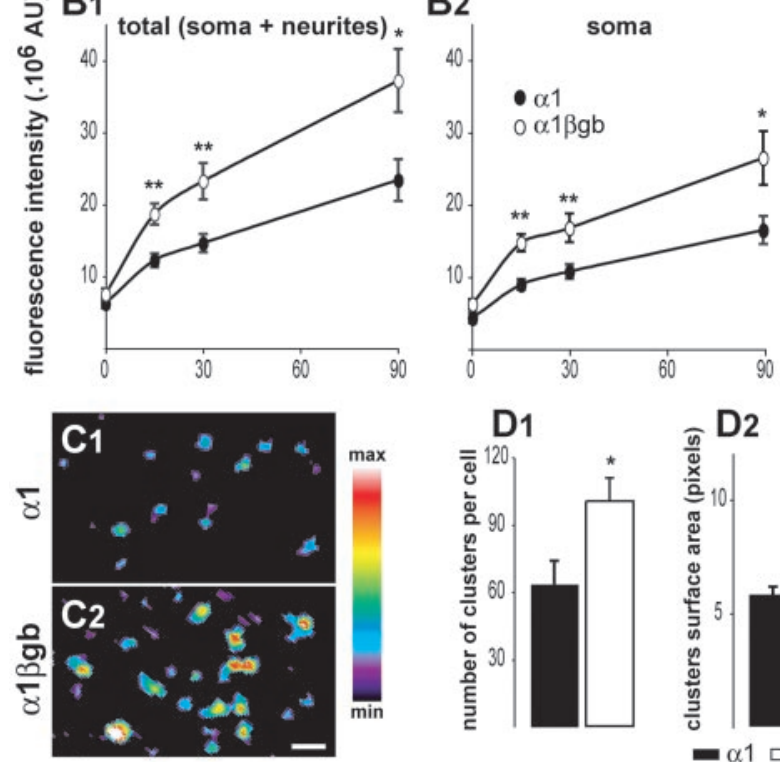

B3
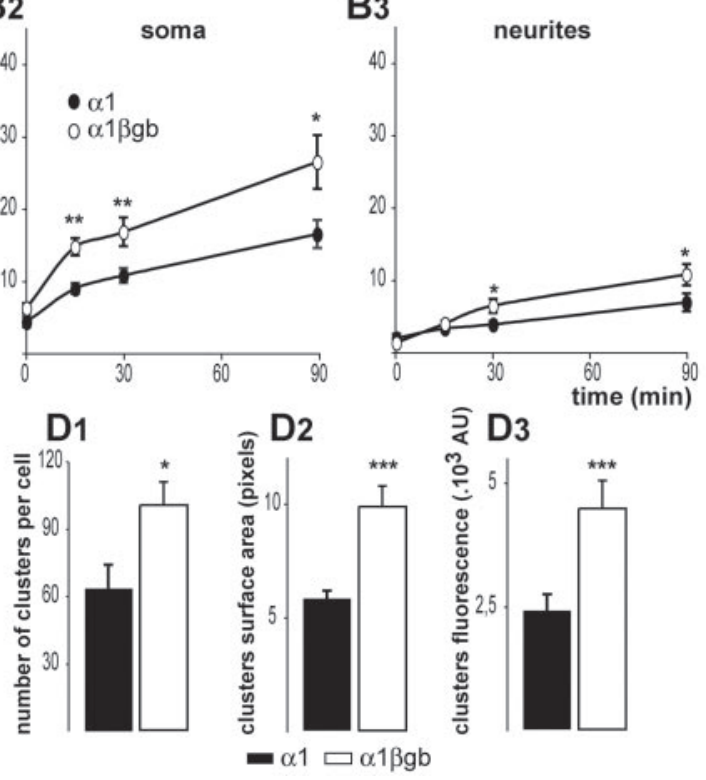

Figure 6. Gephyrin expression increases the amount of GlyR at the cell surface of cultured neurons. Spinal cord neurons (3 DIV) were treated as described in Figure 5. Fluorescence quantifications on confocal sections are shown (see Materials and Methods). $A$, Projections of confocal sections of neurons cotransfected with GlyR $\alpha_{1}(A 1-A 4)$ or GlyR $\alpha_{1} \beta \mathrm{gb}(A 5-A 8)$ and gephyrin::GFP (Ge::GFP), obtained at $0(A 1, A 5), 15(A 2, A 6), 30(A 3, A 7)$, and $90(A 4, A 7)$ min of the restoration phase. Cytoplasm of transfected cells was outlined (red line) using Ge::GFP and MAP2 immunoreactivity-associated fluorescence. Note that the number of GlyR-IR clusters increased with time. Nontransfected cell is indicated by the asterisk in $A 3$ and $A 7$. At $t_{0}+15$ min, surface GlyR clusters were concentrated over the soma (arrowheads) and proximal parts of neurites (arrows). At $t_{0}+30$ and $t_{0}+90$ min, GlyR clusters were detected more distally on neurites (arrows). $B$, Fluorescence recovery measured at somata plus neurites (B1), somata only $(B 2)$, and neurites only $(B 3)$ (mean \pm SEM cell fluorescence; $n=8-23$ cells from three experiments analyzed for each time point and for each transfection condition). As observed for $\operatorname{COS-7}$ cells, the GlyR-associated fluorescence increased with time more rapidly with GlyR $\alpha_{1} \beta \mathrm{gb}$ than with GlyR $\alpha_{1}$. Note that the overall fluorescence recovery was accounted for by a biphasic time course for the soma, with twice as much fluorescence with GlyR $\alpha_{1} \beta \mathrm{gb}$ as with GlyR $\alpha_{1}$, at $15 \mathrm{~min}$. C, GlyR immunoreactivity clusters 15 min after the temperature shift for GlyR $\alpha_{1}(C 1)$ and GlyR $\alpha_{1} \beta \mathrm{gb}(\mathrm{C})$ in cells cotransfected with Ge::GFP (confocal sections, pseudo-color codes for intensity levels). Note the higher fluorescence and larger size of clusters for GlyR $\alpha_{1} \beta \mathrm{gb}$ compared with GlyR $\alpha_{1}$.D, Quantification of GlyR cluster number per cell (D1), cluster surface area (D2), and fluorescence intensity (D3) (means \pm SEM). Note the higher number of clusters per cell, and the increased surface area and fluorescence intensity of individual clusters for GlyR $\alpha_{1} \beta \mathrm{gb}$ compared with that of GlyR $\alpha_{1} ; 1502$ clusters in 15 cells and 771 clusters in 12 cells from three experiments were analyzed for GlyR $\alpha_{1} \beta \mathrm{gb}$ and GlyR $\alpha_{1}$, respectively. Scale bars: $A, 10 ; C, 1 \mu \mathrm{m} .{ }^{*} p<0.05 ;{ }^{* *} p<0.01$; ${ }^{* * *} p<$

GlyR with gephyrin increased not only the number of GlyR clusters but also their size and fluorescence intensity.

Thus, an association of intracellular GlyR with gephyrin could modify receptor trafficking and affect its delivery to synapses. The interaction of gephyrin with $\mathrm{GABA}_{\mathrm{A}} \mathrm{R}$ associated protein (Wang et al., 1999), which presents close homology with p16, an intra- 

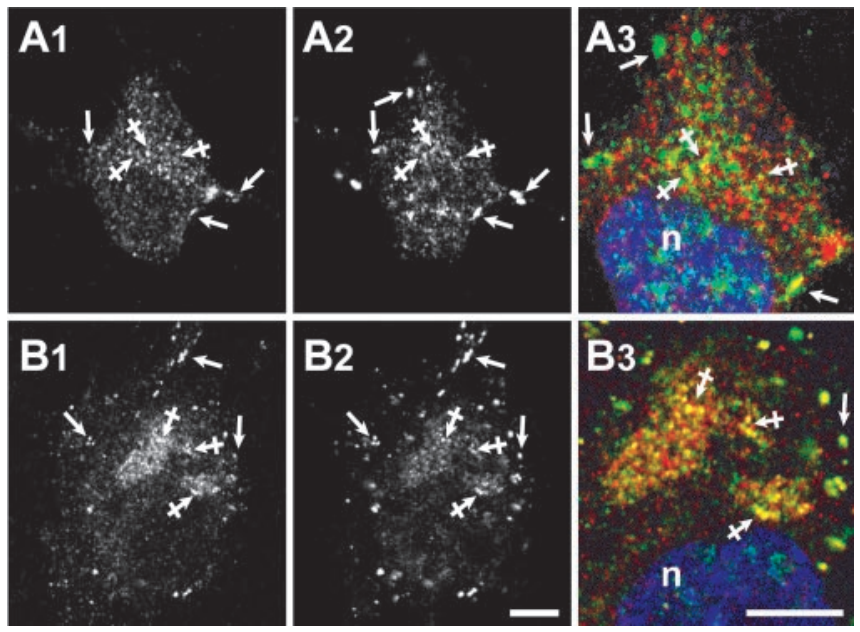

Figure 7. Colocalization of endogenous GlyR and gephyrin in somatic intracellular compartment of neurons at 10 DIV. $A, B$, Confocal sections of two cells labeled with polyclonal anti-GlyR $\alpha_{1}$ and monoclonal anti-gephyrin antibodies. $A 1, B 1$, GlyR-associated fluorescence. $A 2, B 2$, $G$ Gephrin-associated fluorescence. $A 3, B 3$, Superimposition of columns 1 and 2 with GlyR-(red), gephyrin- (green), and DAPI- (blue) associated fluorescences, at higher magnification, showing a colocalization of GlyR and gephyrin puncta in intracellular compartments close to the nucleus (crossed arrows) and at the cell periphery (arrows). n, Nucleus. Scale bars, $5 \mu \mathrm{m}$.

Golgi trafficking factor (Legesse-Miller et al., 1998), could be important in this context, as suggested in the case of the $\mathrm{GABA}_{\mathrm{A}} \mathrm{R}$ (Kneussel et al., 2000; Kittler et al., 2001).

\section{Toward a preconstruction of the postsynaptic membranes}

The notion that GlyR could associate with gephyrin as it is transported from the TGN to the plasma membrane is comparable with that of the association of rapsyn and components of the dystrophin-associated complex with AChR, as suggested by their colocalization in post-Golgi vesicles (Marchand et al., 2000, 2001). Although the direct association of these molecules with intracellular AChR was not demonstrated, these reports support the notion that elements of the neuromuscular junction are delivered to the plasma membrane as preassembled complexes (Marchand and Cartaud, 2002). Other findings in the CNS supported the notion that some postsynaptic proteins involved in the synaptic clustering of NMDA and/or AMPA glutamate receptors, such as PSD-95 (El-Husseini et al., 2000), stargazin (Chen et al., 2000, El-Husseini et al., 2002), synapse-associated protein 97 (Sans et al., 2001), and GRIP/ABP (Dong et al., 1999; DeSouza et al., 2002), may associate with receptors as they traffic to or from the cell surface. Thus, regulation of the neurotransmitter receptors traffic to the cell surface and/or to synapses could stem from their preassembly with components of the PSD. Similarly, several studies have reported that at the presynaptic side many active zone components may be present in and around the same intracellular carriers, and it has been concluded that active zones derive from preassembled precursors (Ahmari et al., 2000; Zhai et al., 2001; Shapira et al., 2003). Therefore, the preassembly in intracellular compartments could be a general mechanism for the construction of presynaptic and postsynaptic membrane microdomains, and may constitute a means of targeting extrinsic membrane-associated proteins to specific membrane loci.

Actually, the traffic of rapsyn or PSD-95 via intracellular membrane is required for the proper targeting of those molecules (Marchand et al., 2002; El-Husseini et al., 2000). The intracellular localization of PSD-95 depends on the palmitoylation near the $\mathrm{N}$ terminal of the molecule, and this acylation also affects the pro- tein clustering activity (El-Husseini et al., 2000) and selfoligomerization (Christopherson et al., 2003) of PSD-95. The ability to oligomerize is a common feature of most postsynaptic anchoring molecules; such is also the case for gephyrin (Kneussel and Betz, 2000). This raises the question of the intracellular trafficking of scaffolding proteins in relation to their ability to form ordered lattices under the plasma membrane and to stabilize membrane proteins.

Finally, two hypotheses may hold: The first is that gephyrin dissociates from GlyR because the latter is inserted in the plasma membrane; the second is that GlyR and gephyrin remain associated because GlyR is inserted in the plasma membrane and that the two molecules diffuse together to be captured at synapses. Two sets of data favor the latter hypothesis: first, as shown in this paper, newly inserted gephyrin-GlyR clusters are brighter and larger than GlyR clusters without gephyrin, suggesting a stabilization of these aggregates; second, during development $~ 10 \%$ of membrane-associated clusters of gephyrin are extrasynaptic (Levi et al., 1999; Dumoulin et al., 2000), suggesting that they are kinetic intermediates toward synapses. Yet the interaction of surface GlyR with submembranous gephyrin aggregates is a reversible process (Meier et al., 2001) and receptors may enter or exit the postsynaptic differentiation via a diffusive process within the plane of the membrane (Dahan et al., 2003). These observations led to a model in which GlyR is in equilibrium between synaptic and extrasynaptic pools (Choquet and Triller, 2003). We therefore postulate that the sequence of events is as follows: GlyR and gephyrin associate as they are transported toward the plasma membrane, preassembled GlyR-gephyrin complexes are inserted in the somatodendritic membrane, they diffuse and are captured at synapses to form postsynaptic microdomains, and GlyR may dissociate from synaptic or extrasynaptic GlyRgephyrin clusters.

\section{References}

Ahmari SE, Buchanan J, Smith SJ (2000) Assembly of presynaptic active zones from cytoplasmic transport packets. Nat Neurosci 3:445-451.

Bechade C, Colin I, Kirsch J, Betz H, Triller A (1996) Expression of glycine receptor alpha subunits and gephyrin in cultured spinal neurons. Eur J Neurosci 8:429-435.

Chen L, Chetkovich DM, Petralia RS, Sweeney NT, Kawasaki Y, Wenthold RJ, Bredt DS, Nicoll RA (2000) Stargazin regulates synaptic targeting of AMPA receptors by two distinct mechanisms. Nature 408:936-943.

Choquet D, Triller A (2003) The role of receptor diffusion in the organization of the postsynaptic membrane. Nat Rev Neurosci 4:251-265.

Christopherson KS, Sweeney NT, Craven SE, Kang R, El-Husseini Ael D, Bredt DS (2003) Lipid- and protein-mediated multimerization of PSD95: implications for receptor clustering and assembly of synaptic protein networks. J Cell Sci 116:3213-3219.

Colin I, Rostaing P, Triller A (1996) Gephyrin accumulates at specific plasmalemma loci during neuronal maturation in vitro. J Comp Neurol 374:467-479.

Colin I, Rostaing P, Augustin A, Triller A (1998) Localization of components of glycinergic synapses during rat spinal cord development. J Comp Neurol 398:359-372.

Craven SE, Bredt DS (1998) PDZ proteins organize synaptic signaling pathways. Cell 93:495-498.

Dahan M, Lévi S, Luccardini C, Rostaing P, Riveau B, Triller A (2003) Diffusion dynamics of glycine receptors revealed by single quantum dot tracking. Science 302:442-445.

DeSouza S, Fu J, States BA, Ziff EB (2002) Differential palmitoylation directs the AMPA receptor-binding protein $\mathrm{ABP}$ to spines or to intracellular clusters. J Neurosci 22:3493-3503.

Dong H, Zhang P, Liao D, Huganir RL (1999) Characterization, expression and distribution of GRIP protein. Ann NY Acad Sci 868:535-540.

Dumoulin A, Levi S, Riveau B, Gasnier B, Triller A (2000) Formation of 
mixed glycine and GABAergic synapses in cultured spinal cord neurons. Eur J Neurosci 12:3883-3892.

El-Husseini AE, Craven SE, Chetkovich DM, Firestein BL, Schnell E, Aoki C, Bredt DS (2000) Dual palmitoylation of PSD-95 mediates its vesiculotubular sorting, postsynaptic targeting, and ion channel clustering. J Cell Biol 148:159-172.

El-Husseini Ael-D, Schnell E, Dakoji S, Sweeney N, Zhou Q, Prange O, Gauthier-Campbell C, Aguilera-Moreno A, Nicoll RA, Bredt DS (2002) Synaptic strength regulated by palmitate cycling on PSD-95. Cell 108:849-863.

Essrich C, Lorez M, Benson JA, Fritschy JM, Luscher B (1998) Postsynaptic clustering of major GABAA receptor subtypes requires the gamma 2 subunit and gephyrin. Nat Neurosci 1:563-571.

Feng G, Tintrup H, Kirsch J, Nichol MC, Kuhse J, Betz H, Sanes JR (1998) Dual requirement for gephyrin in glycine receptor clustering and molybdoenzyme activity. Science 282:1321-1324.

Fuhrmann JC, Kins S, Rostaing P, El Far O, Kirsch J, Sheng M, Triller A, Betz H, Kneussel M (2002) Gephyrin interacts with dynein light chains 1 and 2, components of motor protein complexes. J Neurosci 22:5393-5402.

Griffiths G, Pfeiffer S, Simons K, Matlin K (1985) Exit of newly synthesized membrane proteins from the trans cisterna of the Golgi complex to the plasma membrane. J Cell Biol 101:949-964.

Ho WC, Allan VJ, van Meer G, Berger EG, Kreis TE (1989) Reclustering of scattered Golgi elements occurs along microtubules. Eur J Cell Biol 48:250-263.

Kennedy MB (2000) Signal-processing machines at the postsynaptic density. Science 290:750-754.

Kins S, Betz H, Kirsch J (2000) Collybistin, a newly identified brain-specific GEF, induces submembrane clustering of gephyrin. Nat Neurosci 3:22-29.

Kirsch J, Betz H (1998) Glycine-receptor activation is required for receptor clustering in spinal neurons. Nature 392:717-720.

Kirsch J, Langosch D, Prior P, Littauer UZ, Schmitt B, Betz H (1991) The 93-kDa glycine receptor-associated protein binds to tubulin. J Biol Chem 266:22242-22245.

Kirsch J, Wolters I, Triller A, Betz H (1993) Gephyrin antisense oligonucleotides prevent glycine receptor clustering in spinal neurons. Nature 366:745-748.

Kittler JT, Rostaing P, Schiavo G, Fritschy JM, Olsen R, Triller A, Moss SJ (2001) The subcellular distribution of GABARAP and its ability to interact with NSF suggest a role for this protein in the intracellular transport of GABA(A) receptors. Mol Cell Neurosci 18:13-25.

Kneussel M, Betz H (2000) Clustering of inhibitory neurotransmitter receptors at developing postsynaptic sites: the membrane activation model. Trends Neurosci 23:429-435.

Kneussel M, Haverkamp S, Fuhrmann JC, Wang H, Wassle H, Olsen RW, Betz H (2000) The gamma-aminobutyric acid type A receptor (GABAAR)-associated protein GABARAP interacts with gephyrin but is not involved in receptor anchoring at the synapse. Proc Natl Acad Sci USA 97:8594-8599.

Langford GM (2002) Myosin-V, a versatile motor for short-range vesicle transport. Traffic 3:859-865.

Legesse-Miller A, Sagiv Y, Porat A, Elazar Z (1998) Isolation and characterization of a novel low molecular weight protein involved in intra-Golgi traffic. J Biol Chem 273:3105-3109.

Levi S, Vannier C, Triller A (1998) Strychnine-sensitive stabilization of postsynaptic glycine receptor clusters. J Cell Sci 111:335-345.

Levi S, Chesnoy-Marchais D, Sieghart W, Triller A (1999) Synaptic control of glycine and $\mathrm{GABA}_{\mathrm{A}}$ receptors and gephyrin expression in cultured motoneurons. J Neurosci 19:7434-7449.

Mammoto A, Sasaki T, Asakura T, Hotta I, Imamura H, Takahashi K, Matsuura Y, Shirao T, Takai Y (1998) Interactions of drebrin and gephyrin with profilin. Biochem Biophys Res Commun 243:86-89.

Marchand S, Cartaud J (2002) Targeted trafficking of neurotransmitter receptors to synaptic sites. Mol Neurobiol 26:117-135.

Marchand S, Bignami F, Stetzkowski-Marden F, Cartaud J (2000) The myristoylated protein rapsyn is cotargeted with the nicotinic acetylcholine receptor to the postsynaptic membrane via the exocytic pathway. J Neurosci 20:521-528.

Marchand S, Stetzkowski-Marden F, Cartaud J (2001) Differential targeting of components of the dystrophin complex to the postsynaptic membrane. Eur J Neurosci 13:221-229.

Marchand S, Devillers-Thiery A, Pons S, Changeux JP, Cartaud J (2002) Rapsyn escorts the nicotinic acetylcholine receptor along the exocytic pathway via association with lipid rafts. J Neurosci 22:8891-8901.

Matlin KS, Simons K (1983) Reduced temperature prevents transfer of a membrane glycoprotein to the cell surface but does not prevent terminal glycosylation. Cell 34:233-243.

Mays RW, Beck KA, Nelson WJ (1994) Organization and function of the cytoskeleton in polarized epithelial cells: a component of the protein sorting machinery. Curr Opin Cell Biol 6:16-24.

Meier J, Meunier-Durmort C, Forest C, Triller A, Vannier C (2000a) Formation of glycine receptor clusters and their accumulation at synapses. J Cell Sci 113:2783-2795.

Meier J, De Chaldee M, Triller A, Vannier C (2000b) Functional heterogeneity of gephyrins. Mol Cell Neurosci 16:566-577.

Meier J, Vannier C, Serge A, Triller A, Choquet D (2001) Fast and reversible trapping of surface glycine receptors by gephyrin. Nat Neurosci 4:253-260.

Meyer G, Kirsch J, Betz H, Langosch D (1995) Identification of a gephyrin binding motif on the glycine receptor beta subunit. Neuron 15:563-572.

Moss SJ, Smart TG (2001) Constructing inhibitory synapses. Nat Rev Neurosci 2:240-250.

Naisbitt S, Valtschanoff J, Allison DW, Sala C, Kim E, Craig AM, Weinberg RJ, Sheng M (2000) Interaction of the postsynaptic density-95/guanylate kinase domain-associated protein complex with a light chain of myosin-V and dynein. J Neurosci 20:4524-4534.

Prior P, Schmitt B, Grenningloh G, Pribilla I, Multhaup G, Beyreuther K, Maulet Y, Werner P, Langosch D, Kirsch J (1992) Primary structure and alternative splice variants of gephyrin, a putative glycine receptor-tubulin linker protein. Neuron 8:1161-1170.

Rasmussen H, Rasmussen T, Triller A, Vannier C (2002) Strychnineblocked glycine receptor is removed from synapses by a shift in insertion/ degradation equilibrium. Mol Cell Neurosci 19:201-215.

Roche KW, Tu JC, Petralia RS, Xiao B, Wenthold RJ, Worley PF (1999) Homer $1 \mathrm{~b}$ regulates the trafficking of group I metabotropic glutamate receptors. J Biol Chem 274:25953-25957.

Rosenberg M, Meier J, Triller A, Vannier C (2001) Dynamics of glycine receptor insertion in the neuronal plasma membrane. J Neurosci 21:5036-5044

Sans N, Racca C, Petralia RS, Wang YX, McCallum J, Wenthold RJ (2001) Synapse-associated protein 97 selectively associates with a subset of AMPA receptors early in their biosynthetic pathway. J Neurosci 21:7506-7516.

Saxton MJ (1993) Lateral diffusion in an archipelago. Single-particle diffusion. Biophys J 64:1766-1780.

Saxton MJ (1997) Single-particle tracking: the distribution of diffusion coefficients. Biophys J 72:1744-1753.

Scannevin RH, Huganir RL (2000) Postsynaptic organization and regulation of excitatory synapses. Nat Rev Neurosci 1:133-141.

Seitanidou T, Nicola MA, Triller A, Korn H (1992) Partial glycinergic denervation induces transient changes in the distribution of a glycine receptor-associated protein in a central neuron. J Neurosci 12:116-131.

Shapira M, Zhai RG, Dresbach T, Bresler T, Torres VI, Gundelfinger ED, Ziv NE, Garner CC (2003) Unitary assembly of presynaptic active zones from Piccolo-Bassoon transport vesicles. Neuron 38:237-252.

Toomre D, Keller P, White J, Olivo JC, Simons K (1999) Dual-color visualization of trans-Golgi network to plasma membrane traffic along microtubules in living cells. J Cell Sci 112:21-33.

Wang H, Bedford FK, Brandon NJ, Moss SJ, Olsen RW (1999) GABA(A)receptor-associated protein links $\mathrm{GABA}(\mathrm{A})$ receptors and the cytoskeleton. Nature 397:69-72.

Zhai RG, Vardinon-Friedman H, Cases-Langhoff C, Becker B, Gundelfinger ED, Ziv NE, Garner CC (2001) Assembling the presynaptic active zone: a characterization of an active one precursor vesicle. Neuron 29:131-143. 